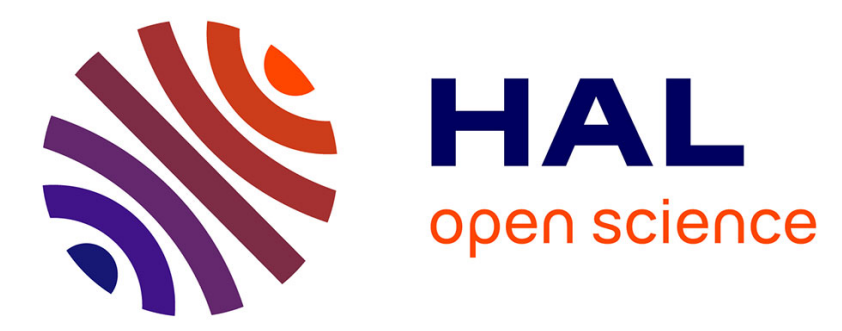

\title{
Theoretical studies on aromaticity of selected hydroxypyrones. Part 3. Chelatoaromaticity phenomenon in metalcomplexes of hydroxypyrones.
} Krzysztof Zborowski, Miquel Sola, Jordi Poater, Leonard Proniewicz

\section{- To cite this version:}

Krzysztof Zborowski, Miquel Sola, Jordi Poater, Leonard Proniewicz. Theoretical studies on aromaticity of selected hydroxypyrones. Part 3. Chelatoaromaticity phenomenon in metalcomplexes of hydroxypyrones.. Journal of Physical Organic Chemistry, 2010, 24 (6), pp.499. 10.1002/poc.1794 . hal-00599804

\section{HAL Id: hal-00599804 \\ https://hal.science/hal-00599804}

Submitted on 11 Jun 2011

HAL is a multi-disciplinary open access archive for the deposit and dissemination of scientific research documents, whether they are published or not. The documents may come from teaching and research institutions in France or abroad, or from public or private research centers.
L'archive ouverte pluridisciplinaire HAL, est destinée au dépôt et à la diffusion de documents scientifiques de niveau recherche, publiés ou non, émanant des établissements d'enseignement et de recherche français ou étrangers, des laboratoires publics ou privés. 


\section{Journal of Physical Organic Chemistry}

WILEY

Theoretical studies on aromaticity of selected hydroxypyrones. Part 3. Chelatoaromaticity phenomenon in metalcomplexes of hydroxypyrones.

\begin{tabular}{|r|l|}
\hline Journal: & Journal of Physical Organic Chemistry \\
\hline Manuscript ID: & POC-10-0057.R1 \\
\hline Wiley - Manuscript type: & Research Article \\
\hline Date Submitted by the & 04-Aug-2010 \\
\hline Complete List of Authors: & $\begin{array}{l}\text { Zborowski, Krzystof; Jagiellonian University, Chemical Physics } \\
\text { Sola, Miquel; University of Girona, Quimica } \\
\text { Poater, Jordi; University of Girona, Quimica } \\
\text { Proniewicz, Leonard; Jagiellonian University, Chemistry }\end{array}$ \\
\hline Keywords: & $\begin{array}{l}\text { hydroxypyrones, chelatocomplexes, aromaticity, } \\
\text { metalloaromaticity, density functional theory }\end{array}$ \\
\hline
\end{tabular}

\section{SCHOLARONE ${ }^{\text {Tw }}$ Manuscripts}


Theoretical studies on aromaticity of selected hydroxypyrones. Part $3^{\#}$.

Chelatoaromaticity phenomenon in metalcomplexes of hydroxypyrones

Short title: Chelatoaromaticity in hydroxypyrones metalcomplexes.

\author{
Krzysztof K. Zborowski ${ }^{a *}$, Miquel Solà ${ }^{b}$, Jordi Poater ${ }^{b}$, Leonard M. Proniewicz ${ }^{a, c}$ \\ ${ }^{a}$ Faculty of Chemistry, Jagiellonian University, 3 Ingardena Str., 30-060 Kraków, Poland \\ ${ }^{b}$ Institut de Química Computacional and Departament de Química, Universitat de Girona, \\ Campus de Montilivi, 17071 Girona, Catalonia, Spain \\ ${ }^{c}$ Regional Laboratory of Physicochemical Analyses and Structural Research, \\ Jagiellonian University, 3 Ingardena Str., 30-060 Kraków, Poland
}

${ }^{*}$ Corresponding author

3 Ingardena Street

30-060 Krakow, Poland

tel.: +48-12-633-63-77/ext. 2067

fax: $+48-12-634-05-15$

e-mail address zborowsk@ chemia.uj.edu.pl (K. K. Zborowski)

\#Part 1: Zborowski, K.; Grybos, R.; Proniewicz, L. M. J. Phys. Org. Chem. 2005, 18, 250-254

\#Part 2: Zborowski, K.; Proniewicz, L. M. J. Phys. Org. Chem. 2008, 21, 207-214 


\begin{abstract}
:
The aim of this project is to study the aromatic properties of various forms (neutral, cationic and anionic) of selected hydroxypyrones (pyromeconic acid, maltol, ethylmaltol) and their metal complexes with aluminium, gallium, and indium ions. Aromaticity of hydroxypyrone metalcomplexes is important because it can influence the stability of such complexes, which is crucial for their applications in medicinal and environmental chemistry.

Results from ten different indices of aromaticity (HOMA, NICS(0), NICS(1) NICS $_{\text {scan, }}$, $\mathrm{ASE}_{\text {iso }}, \mathrm{PDI}, \mathrm{FLU}, \mathrm{I}_{\text {ring }}, \mathrm{MCI}$, and KMCI) show that aromaticity in hydroxypyrones decreases in the order cations $>$ neutral molecules $>$ anions. Performed calculations situate the aromaticities of ligands in metal complexes close to their respective cations. This means that complexation causes a significant increase of the aromaticity of ligands, which stabilizes formed chelatocomplexes. On the other hand, we clearly show that rings that are involved in binding metal ions are not aromatic.
\end{abstract}

Keywords: hydroxypyrones, chelatocomplexes, aromaticity, metalloaromaticity, density functional theory 


\section{Introduction}

The family of hydroxypyrones together with closely related hydroxypyridinones forms a class of ligands with many potential applications in medicinal chemistry. ${ }^{[1]}$ After deprotonation, these ligands easily form a number of stable complexes with divalent and trivalent metal ions. Because of that, and due to negligible toxicity, they can be used as agents for in situ metal ion complex formation and subsequent removal of metal ions excess from the body. On the other hand, their metalcomplexes are tested as new drugs designed for improving absorption and biodistribution of metal ions. Diseases such as anemia, thallassemia and diabetes are the most important examples. Potential applications of hydroxypyrones and hydroxypyridinones in diabetic therapy ${ }^{[2-3]}$, iron distribution ${ }^{[4]}$ and aluminium chelation ${ }^{[5-6]}$ were summarized in several critical reviews.

Metal ion complexes are formed by deprotonated hydroxypyrone units, also referred as anions of hydroxypyrones (see Fig. 1). Deprotonated 3-hydroxy-4-pyrone consists of a sixmembered heterocyclic pyran ring with an oxygen atom in para to the ketone group and two ortho exocyclic oxygen atoms (from the ketone and the deprotonated hydroxyl groups). The two exocyclic oxygens and the carbon-carbon bridge between them constitute the so-called OCCO group that is directly responsible for the metal ion complexation. The presence of $\pi$ electrons in hydroxypyrone structures imposes the possibility of aromatic properties of the heterocyclic rings. In addition, the electron delocalization can also be determined in the OCCO group and aromaticity can be analyzed in the heterocyclic and metallocyclic rings after complexation too.

Figure 1, here 
Aromaticity of carbocyclic and heterocyclic compounds is a very popular topic in physical organic chemistry. On the other hand, chelatoaromaticity (aromaticity of chelate complexes) has received rather sporadic interest until recently, despite the fact that such idea was decribed firstly long time ago by Calvin and Wilson. ${ }^{[7]}$ Recently, the concept of chelatoaromaticity has been renewed due to the synthesis of new chelatoaromatic complexes, new developments in the theory of aromaticity, and the recognition of the importance of chelatoaromaticity in prediction of the reaction mechanisms. This concept may also be useful in explaining many properties of chelates that may have appeared unlinked. For example, the electronic, vibrational, and NMR spectra, as well as the electrochemistry, and X-ray structure can be interpreted as a result of chelatoaromaticity induced by the metal ions. ${ }^{[8]}$ For us, the most important point is that aromatic effects should influence the stability of metalcomplexes of hydroxypyrones. Chelatoaromatic stabilization can be important in cases where a nonaromatic or antiaromatic ligand coordinates to the metal ion and after coordination it gains aromatic character. An increase of the aromatic character in the metalcomplex provides an additional stabilization of the complex.

Aromaticity is a term that still is not precisely defined. Some aspects of its definition are still discussed. ${ }^{[9-10]}$ That's why in the last few years we have focused our studies on selected, very well define group of ligands, i.e. hydroxypyrones to support such studies. In this paper we want to show how procedure used by us can be useful in developments of this topics in chemistry of chelate compounds. Thus, in the present work, we investigate the chelatoaromaticity phenomenon in metalcomplexes of some hydroxypyrones (pyromeconic acid, maltol and ethylmaltol) with several metal ions, like $\mathrm{Al}^{3+}, \mathrm{Ga}^{3+}$ and $\mathrm{In}^{3+}$. Gallium and indium complexes of hydroxypyrones have potential practical importance as they are considered new useful radiopharmaceuticals. ${ }^{[11-12]}$ On the other hand, the aluminium ion maltol complex is used to try to understand the origin of the Alzheimer disease. ${ }^{[13]}$ It is also 


\section{Computational details}

In order to study the basis set effects on the obtained results we performed calculations

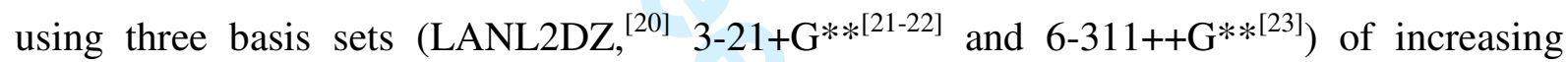
quality. LANL2DZ basis set is a standard core potential approach widely used in metalcomplexes calculations. It is a mixture of the Los Alamos effective core potential with the Dunning/Huzinaga valence double zeta basis set for the first row of elements and a double zeta basis set for the valence electrons for the heavier elements. On the other hand, the 6$311++\mathrm{G}^{* *}$ is a well-qualified basis set enriched with diffusion and polarization functions. Unfortunately, this basis set is unavailable for indium. Because of that, available for all studied metals $3-21+\mathrm{G}^{* *}$ basis set was also used. Geometries of all studied compounds were computed at the $\mathrm{B} 3 \mathrm{LYP}^{[24-26]}$ level of theory using all three aforementioned basis sets. All geometries calculated in this work correspond to geometrical minima with no imaginary frequencies. Obtained geometries were used for the calculation of magnetic properties (under the GIAO approximation ${ }^{[27]}$ ) at the same level of theory. All these calculations were computed with the Gaussian03 program. ${ }^{[28]}$ Atoms in Molecules ${ }^{[29]}$ properties were integrated using the AIMPAC package. ${ }^{[30]}$ 
In this work, numerous aromaticity indices were used: geometric (HOMA), magnetic (NICS(0), NICS(1) and $\left.\operatorname{NICS}_{\text {scan }}\right)$, energetic $\left(\mathrm{ASE}_{\text {iso }}\right)$ and various electronic indices of aromaticity (PDI, FLU, Iring, MCI and KMCI).

HOMA index (Harmonic Oscillator Model of Aromaticity ${ }^{[31]}$ is calculated using bond lenghts of the studied systems by means of the equation:

$$
H O M A=1-\frac{\alpha}{n} \sum_{i=1}^{n}\left(R_{o p t}-R_{i}\right)^{2}
$$

where $R_{o p t}$ and $R_{i}$ are optimal bond lengths and bond lengths in the real system, respectively. The variable $\alpha$ is an empirical factor chosen to provide a HOMA value of 0 for the Kekule structure of benzene and a value of 1 for the real benzene with "aromatic" bond lengths. Finally, $n$ is the number of bonds in the system under consideration. In this paper, the HOMA index has been used for evaluation of electron delocalization efficiency in the heterocyclic ring and the OCCO group of all studied compounds.

The NICS (Nucleus Independent Chemical Shift) index of aromaticity is based on the magnetic properties of aromatic compounds. ${ }^{[32]}$ It is defined as the negative value of the absolute magnetic shielding. It can be calculated in the center of the aromatic ring or fragment determined by the non-weighted mean of the heavy atoms coordinates (NICS(0)), or at $1 \AA$ above it (NICS(1)). Negative NICS values denote efficient electron delocalization. In this work, NICS values were determined for heterocyclic and metallocyclic rings of studied ligands and metalcomplexes. More comprehensive NICS approach is the NICS scan $_{\text {method. }}{ }^{[33]}$ Magnetic properties necessary for NICS $_{\text {scan }}$ presentation were calculated from the ring center to $4.9 \AA$ above it, with a step size of $0.1 \AA$ along the line (normal) perpendicular to the ring plane.

Another very important property of aromatic compounds is their higher stability with respect to a structurally analogue model system which has no cyclic electronic delocalization. For such purpose, the calculation of the Aromatic Stabilization Energy (ASE) is the core of 
aromaticity research based on energetic basis. Unfortunately, there are a lot of problems with defining the reasonable non-aromatic reference state. ${ }^{[34]}$ One of the highly recommended methods for the estimation of ASE is the "isomerization method" based on the enthalpy difference between a methyl derivative of the aromatic system and its non-aromatic exocyclic methylene isomer. ${ }^{[35]}$ There are several possible places for isomerization in the case of studied hydroxypyrones. Among them we have chosen the one presented on the Scheme below (example of the neutral molecule of hydroxypyrones). Such localization of the isomerization place let us avoid changes in the type of the metal ion interactions with investigated ligands. Using the mentioned reaction, $\mathrm{ASE}_{\text {iso }}$ were calculated for neutral form of studied ligands as well as for their anions, cations and metalcomplexes.

Scheme 1, here

Recently, electronic indices of aromaticity have been introduced as a new tool in aromaticity research. ${ }^{[36]}$ The simplest index from this group is the PDI (para delocalization index). It is defined as the mean of the electronic delocalization indices (DI) calculated in the frame of the AIM theory for para-related atoms in the rings. ${ }^{[37]}$ PDI values can be only calculated for six-membered rings. FLU is another aromaticity index based directly on electron delocalization that can be applied to heterocyclic rings of hydroxypyrones and their metalcomplexes. FLU measures the number of electrons shared between consecutive atoms in the ring. ${ }^{[38]}$ The small drawback of the FLU index in our calculation is that there is no reference FLU parameter for the carbon-oxygen bond (because it is difficult to find the fully aromatic compound with such a bond in its ring). For this reason, the FLU parameters determined for the carbon-carbon bond have been used for the carbon-oxygen bonds too.

Finally, so-called multicenter aromaticity indices, namely: $\mathrm{I}_{\mathrm{ring}}$, MCI, and KMCI, have been also calculated. These indices do not estimate delocalization between pairs of atoms, but 
take into account delocalization in the whole ring. Details are described in original papers. ${ }^{[39-}$ ${ }^{41]} \mathrm{I}_{\text {ring, }}$ MCI and KMCI indices are useful as aromaticity indicators of both heterocyclic and metallocyclic rings of studied compounds. In recent papers ${ }^{[19,42]}$, it has been shown that the MCI and $\mathrm{I}_{\text {ring }}$ indices are among the most reliable measures of aromaticity.

\section{Results and Discussion}

This section is divided into two parts. First the aromaticity of various forms (neutral, cationic, anionic) of three hydroxypyrones together with their metal complexes is presented. Then, the effect of the basis set in the results obtained is briefly discussed.

\section{A. Aromaticity of hydroxypyrones}

Aromaticity properties of three hydroxypyrones: pyromeconic acid (3-hydroxy-4Hpyran-4-one, abbreviated hereafter as Hpa), maltol (3-hydroxy-2-methyl-4H-pyran-4-one, Hma) and ethylmaltol (3-hydroxy-2-ethyl-4H-pyran-4-one, Hema) have been studied in this project. The neutral, cationic and anionic forms of these compounds, together with their complexes with aluminium, gallium and indium ions, have been taken into account. Molecular structures of neutral, anionic and cationic forms of the pyromeconic acid molecule together with complexes formed by the pyromeconic acid anion with aluminium ion (two isomers: fac and mer are considered) are depicted in Fig.1.

HOMA, NICS(0), and NICS(1) data for studied ligands and their charged species, calculated at the B3LYP/6-311++G** level of theory, were published previously. ${ }^{[43,44]}$ Aromaticity of the heterocyclic ring ${ }^{[43]}$ and electronic delocalization in the OCCO group ${ }^{[44]}$ were considered. Performed calculations revealed that aromaticity of hydroxypyrone cations is higher than for neutral molecules, and anions present the lowest one (cations $>$ neutral > anions). It was also previously documented that aromaticity of the deprotonated 
hydroxypyrone units in metalcomplexes of oxovanadium(IV) with maltol and closely related kojic acid are somewhere between the aromaticity of neutral and cationic forms. ${ }^{[45]}$

Aromaticity data calculated at the B3LYP/6-311++G** level by geometric, magnetic (except NICS $_{\text {scan }}$ ) and electronic indices involved in the investigation are presented in Fig. 2. Fig. 2a depicts the HOMA data for the different forms of the pyromeconic acid and its complexes with $\mathrm{Al}^{3+}$ and $\mathrm{Ga}^{3+}$ ions. One can observe that, the aromaticity of the heterocyclic ring strongly increases from anion to cation. This correlates with the increase of electronic delocalization in the OCCO group from the anion to the cation as well. The aromaticity of the heterocyclic pyran ring in the metalcomplexes is positioned, more or less, in the middle between the neutral pyromeconic acid and its cation. In the case of the OCCO group, the metal complexed systems present an electron delocalization similar to that of the cation. In both cases aromaticity/electron delocalization of the aluminium complexes is slightly higher than for the galium ones.

Figure 2, here

NICS data are presented in Fig. 2b (heterocyclic ring) and Fig. 2c (metallocyclic ring). Relative aromaticities predicted by magnetic indices for the heterocyclic rings of studied compounds are quite similar to those given by HOMA. We observe a strong increase of aromaticity from anion to neutral molecule and to cation (one should remember that the more negative the NICS values the higher the aromaticity), while aromaticity value of the heterocyclic ring in presented metalcomplexes is located in the middle between the values calculated for the cation and the neutral molecule, as for HOMA. It is observed that values of magnetic indices for complexes do not depend on the type of the metal ion, as NICS values for both $\mathrm{Al}$ and $\mathrm{Ga}$ complexes are almost the same. NICS values calculated for the 
metallocyclic rings in studied complexes (Fig 2c) suggest that aromaticity of these rings (despite the relative high delocalization of the OCCO group predicted by the HOMA method) is poor and these rings should be described as non-aromatic. It can be noticed that, contrary to HOMA results, the aromaticity of gallium metalcomplexes is slightly higher.

Values of the electronic indices of aromaticity are presented in Figs. 2d-f. PDI and FLU data can be calculated in our case for the heterocyclic pyran ring only. PDI results perfectly follow the order of the relative aromaticity described for both HOMA and NICS indices. FLU data also follow the same trend with the only exception of the anionic form, which is found to be slightly more aromatic than the neutral. MCI, KMCI and $\mathrm{I}_{\text {ring }}$ data for the heterocyclic ring perfectly follow the aromaticity predictions provided by the previous criteria. Predictions of these methods for metallocyclic rings (Fig. 2f) support the conclusion evaluated on the base of previously presented NICS data. Aromaticity of the metallocyclic rings is low.

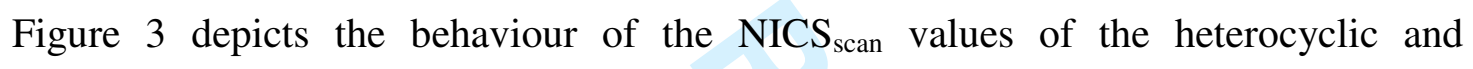
metalocyclic rings of studied compounds. Isotropic chemical shifts as well as the in-plane and out-of-plane components of the chemical shift tensor are presented. The shape of the NICS scan $_{\text {n }}$ curves for all types of heterocyclic rings suggest its aromaticity. ${ }^{[33]}$ From the differences in the depths of minima on the isotropic chemical shift and its out-of-plane component curves we can conclude that aromaticity increases in the order anion $<$ neutral molecule $<$ cation. Aromaticity of the heterocyclic ring of the metalcomplex is between aromaticity of neutral molecule and that of cation. Ring in which metal cation is involved in shows shapes of the NICS $_{\text {scan }}$ curves similar to the ones observed for the anti-aromatic cyclobutadiene. ${ }^{[33]}$

Figure 3, here 
Finally, results of the $\mathrm{ASE}_{\text {iso }}$ calculations are presented in Table 1. These data, in line with the results from the NICS $_{\text {scan }}$ curves, suggest that all studied compounds are aromatic, and that the level of aromaticity increases from anion through neutral molecule and metalcomplexes to the cation.

\section{Table 1, here}

Therefore, with respect to the presented above aromaticity analysis at the B3LYP/6$311++\mathrm{G}^{* *}$ level of theory, it is observed how all geometry-, magnetic-, energetic- and electronic-based (except FLU) criteria assign an increase of aromaticity of the heterocyclic ring of the pyromeconic acid when going from its anionic to neutral and to cationic forms. In addition, the aromaticity of this ring in the complexed systems is almost the same for both $\mathrm{Al}$ and $\mathrm{Ga}$, and is located between that of the previous neutral and cationic forms. Measured by the HOMA method, electron delocalizations of the OCCO group for various forms of hydroxypyrones are similar to the corresponding aromaticity levels of the heterocyclic rings. In addition, all aromaticity indices predict the strong increase of aromaticity of the anion with complexation.

The results presented above for the heterocyclic rings of neutral species, cations and anions can be easily rationalized in several ways. For example, if the Lewis structures depicted in the Scheme 2 are considered, one can recognize that, the most important resonance structure in all cases is the non-aromatic structure a. However the importance of aromatic structures $\mathbf{b}$ and $\mathbf{b}^{\prime}$ decreases in the order cation $>$ neutral $>$ anion. The reason is the fact that in the cation, structures a and b-type differ only by the migration of the positive charge from the oxygen of the ketone group to the oxygen atom of the heterocyclic ring. In the neutral system, the b-type structures have a charge separation that is not present in the 
structure a. That makes these structures less important in the description of the whole molecule, at least in the gas-phase. Finally, in the anionic system, the b-type structures possess also a charge separation but now two local negative charges in two oxygen atoms are placed close to each other. Thus the weight of $\mathbf{b}$-type structures decreases in the order cation $>$ neutral $>$ anion, explaining the reduction of electron delocalization of the heterocyclic ring in the same order. Moreover, the presence of the positive charge metal ion interacting with the two negative charged oxygen atoms in the metalcomplexes stabilizes the b-type structures of the anion and increases its aromaticity. For the same reason, in the anion we have two $\mathrm{O}$ atoms of the OCCO group with very different C-O bond distances (one is a clearly double bond with quite localized pairs of $\pi$-electrons and the other a single bond). The differences are less in the neutral species because the type-b structures become more important and even less in the cationic species in which the weight of type-b structures is especially large.

\section{Scheme 2, here}

Another rationalization of the different aromaticities in various forms of studied hydroxypyrones can be based on variations of the numbers of $\pi$ electrons in the heterocyclic ring. Neutral hydroxypyrone molecule is formally a nonaromatic $7 \pi$-electrons system. However, this system is additionally stabilized by the presence of the very polar carbonyl group, which causes that the actual number of $\pi$-electrons within the cyclic conjugated system gets closer to the aromatic reference of $6{ }^{[46-47]}$ Deprotonation of the hydroxyl group in the anionic form of hydroxypyrones results in a strong $\pi$-donating substituent leading to an increase of the actual number of $\pi$-electrons within the heterocyclic ring, making it less aromatic. A similar effect may be obtained by decreasing the polarity of the exocyclic double bond from $\mathrm{C}=\mathrm{O}$ to $\mathrm{C}=\mathrm{CH}_{2} \cdot{ }^{[48-49]}$ On the other hand, the protonation of the carbonyl oxygen in 


\section{B. Effect of the basis set on the aromaticity results}

In order to show the influence of the basis set quality we performed calculations of aromaticity with three different basis sets: LANL2DZ, $3-21+\mathrm{G}^{* *}$ and $6-311++\mathrm{G}^{* *}$. Calculations have been carried out at the optimized geometries obtained with each of the basis set. Calculated values of the aromaticity indices in these three basis sets for all pyromeconic acid forms and complexes are presented in Fig. 4. These data lead to the conclusion that aromaticity measures are affected by the chosen basis set, the extent of that influence depends on the chosen criterion of aromaticity.

Figure 4, here

In the case of the HOMA (see Figs. $4 \mathrm{a}$ and $4 \mathrm{~b}$ ), we have a simple and direct relationship, that is, the better the basis set the higher the HOMA values, which means higher aromaticity. It is true for both the heterocyclic ring and the electronic delocalization in the OCCO group, although in the case of the heterocyclic ring the difference between $3-21+\mathrm{G}^{* *}$ and LANL2DZ is really small. The largest difference is observed between $6-311++\mathrm{G}^{* *}$ and LANL2DZ basis sets. Data provided by the middle quality $3-21+\mathrm{G}^{* *}$ basis set is closer to LANL2DZ. It must be said that all three basis sets follow the same aromaticity trends, already discussed in the previous section. 
The variation of both NICS(0) and NICS(1) values with the basis set (Fig. 4c and 4d) are not so pronounced as for the HOMA method. In this case there is no direct relationship, and even the curves present crossings, although again all basis sets give the expected trend of an increase of aromaticity for the heterocyclic rings of studied compounds from the anionic to the cationic forms, and the aromaticity of the metal complexes located between those of the neutral and cationic species. Aromaticity of metallocyclic rings is found to be poor for all basis sets.

In the case of PDI and FLU indices (Fig. 4e) different tendencies are observed depending on the basis set. FLU index shows how the better basis set $\left(6-311++\mathrm{G}^{* *}\right)$ gives smaller aromaticity for hydroxypyrone's anion than for neutral molecule, against to all other indices. It is interesting that the FLU with the $3-21+\mathrm{G}^{* *}$ reproduces correctly the aromaticity of the pyromeconic acid anion. The aromaticity order obtained in the frame of the PDI method follow the expected trend for the two basis sets.

On the other hand, shapes of the aromaticity curves of the three multicenter indices ( $\mathrm{I}_{\text {ring }}, \mathrm{MCI}$, and KMCI) are qualitatively similar to each other (see Fig. 4f), and all of them follow the expected trend for the heterocyclic ring. The only difference is the gap between values predicted by both basis sets for a particular index, as larger differences are observed for the $\mathrm{I}_{\mathrm{ring}}$ and MCI indices, whereas the values predicted for the KMCI method are closer, but in all cases the smaller basis set predicts a higher aromaticity. It is likely that multicenter indices provide the best data for the metallocyclic ring (it is possible that NICS predictions for the metallocyclic rings are somewhat perturbed by the presence of the metal at close distance $\left.{ }^{[50]}\right)$. It is clearly seen how the aromaticity predicted by these multicenter indices for the metallocyclic ring is always much lower than for the pyran rings. It is also observed how, in the case of metallocyclic rings, the results are quite insensitive to the aromaticity index and the basis set used for the calculation. On the basis of these results and presented above NICS 
data for the metallocyclic rings we can conclude that rings containing metal ions are nonaromatic. The aromaticity of both the heterocyclic and the metallocyclic rings is only slightly changed along the series of $\mathrm{Al}^{+3}, \mathrm{Ga}^{+3}$ to $\mathrm{In}^{+3}$.

Finally, we want to compare the aromaticities of the Hpa metalcomplexes with those formed by other studied ligands, Hma and Hema, using data obtained based on the 6$311++\mathrm{G}^{* *}$ basis set. The corresponding tables enclosing all aromaticity measures calculated on the B3LYP/6-311++G** level of theory can be found in the Supporting Information. As expected from the structures in Scheme 2, both Hma and Hema present the same behavior as Hpa. Similarly, we observe an increase of aromaticity from the anionic form to the cationic one, and that of the metalcomplexes is located between the neutral and the cationic forms. Even if the aromaticity values for the equivalent forms with the different ligands are quite similar, the substitution of the hydrogen atom by a methyl or an ethyl group at the position 2 of the ring affects neither the aromaticity of the heterocyclic ring nor the electron delocalization in the OCCO group. This shows that in order to have a significant substituent effect on the aromaticity of the heterocyclic ring one needs to place in R position substituents with strong $\pi$-donor (such as $\mathrm{NR}_{2}$ ) or $\pi$-acceptor character (such as $\mathrm{NO}_{2}$ ) that can modify the $\pi$-population of the ring. Preliminary calculations suggest that strong $\pi$-donor or $\pi$-acceptor character substituents can modify the $\pi$-population of the ring and significantly change its aromaticity.

\section{Conclusions}

In the present work we have shown that electronic indices of aromaticity (FLU, PDI, $\mathrm{I}_{\text {ring, }} \mathrm{MCI}$, and $\mathrm{KMCI}$ ) support the aromaticity order of various hydroxypyrones forms, previously established on the base of the results served by some "classical" indices like 
HOMA and NICS. The same is observed for the $\mathrm{NICS}_{\text {scan }}$ and $\mathrm{ASE}_{\text {iso }}$ data. This order states that aromaticity of the anionic form of hydroxypyrones is very low, aromaticity of neutral molecules is moderate, and hydroxypyrone cations are aromatic.

Existence of the chelatoaromaticity phenomenon in complexes of studied hydroxypyrones with aluminium, gallium, and indium ions has been documented. When low aromatic anions of studied ligands coordinate to metal ions, their aromatic properties change very significantly, and they become quite aromatic species. Aromaticity of the heterocyclic ring in studied metalcomplexes is located somewhere between the neutral and the cationic forms of the hydroxypyrone. It seems that the electronic delocalization increase takes also place in the part of the ligand that is directly bonded to the metal ion. On the other hand, the analysis of the metallocyclic rings show that electron delocalization in the whole metallocyclic ring is low. For this reason, the metallocyclic rings must be classified as nonaromatic.

Our study also show that the different hydroxypyrones (pyromeconic acid, maltol and ethylmaltol), present very similar aromaticities in groups of their anionic, neutral or cationic forms, as well as the corresponding metalcomplexes (with either $\mathrm{Al}^{3+}, \mathrm{Ga}^{3+}$ or $\mathrm{In}^{3+}$ ), respectively.

It has to be stressed out that the used for calculations basis set plays crucial role. One cannot use different basis sets for comparison (aromaticity values) of obtained results for the same ligands, although the trends in aromaticity trends remains almost invariant.

Higher aromaticity denotes higher stability. So, an increase of the electron delocalization in hydroxypyrones with complexation should have an important impact on the stability of the studied metalcomplexes. Further research is underway trying to estimate their (chelato)aromatic stabilization energies in order to know if they can be important for their chemistry. 


\section{Acknowledgements}

The work has been performed under the Project HPC-EUROPA (RII3-CT-2003506079), with the support of the European Community - Research Infrastructure Action under the FP6 "Structuring the European Research Area" Programme. We thank the Spanish MEC (project CTQ2008-03077/BQU) and the Catalan DIUE (project 2009SGR-637) for their financial support. J.P. thanks the MEC for the Ramón y Cajal contract. Support for the research of M.S. was received through the ICREA Academia 2009 prize for excellence in research funded by the DIUE of the Generalitat de Catalunya. Authors kindly acknowledge Barcelona Supercomputer Center - Centre Nacional de Supercomputació (BSC-CNS) and Warsaw University's Interdisciplinary Centre for Mathematical and Computational Modelling "ICM" (project number G17-8) for computational facilities.

\section{Supplementary material}

Numerical values of aromaticity indices for all studied compounds calculated at the B3LYP/6-311++G** level of theory. This material is freely available in Wiley Interscience. 


\section{References}

[1] K. H. Thompson, C. A. Barta, C. Orvig, Chem. Soc. Rev. 2006, 35, 545.

[2] K. H. Thompson, C. Orvig, Coord. Chem. Rev. 2001, 219, 1033.

[3] K. H. Thompson, B. D. Liboiron, G. R. Hanson, C. Orvig, in: Medicinal Inorganic Chemistry, (Eds: J.L. Sessler, S.R. Doctrow, T.J. McMurry, S.J. Lippard) ACS, Washington D.C., 2005.

[4] Z. D. Liu, R. C. Hider, Med. Res. Rev. 2002, 22, 26.

[5] R. A. Yokel, Coord. Chem. Rev. 2002, 228, 97.

[6] M. A. Santos, Coord. Chem. Rev. 2002, 228, 187.

[7] M. Calvin, K. W. Wilson, J. Am. Chem. Soc. 1945, 67, 2003.

[8] H. Masui, Coord. Chem. Rev. 2001, 219-221, 957.

[9] P.v.R. Schleyer, H. J. Jiao, Pure \& Appl. Chem. 1996, 68, 209.

[10] A. Stanger, Chem Commun. 2009, 1939.

[11] M. M Finnegan, T. G. Lutz, W. O. Nelson, A Smith, C. Orvig, Inorg. Chem. 1987, 26, 2171.

[12 ] V. Monga, B. O. Patrick, C. Orvig, Inorg. Chem. 2005, 44, 2666.

[13] J. A. Lewis, D. T. Puerta, S. M. Cohen, Inorg. Chem. 2003, 42, 7455.

[14] M. K. Cyrański, T. M. Krygowski, Polish. J. Chem. 1995, 69, 1080.

[15] M. K. Cyrański, T. M. Krygowski, Polish. J. Chem. 1995, 69, 1088.

[16] M. K. Cyrański, T. M. Krygowski, A. R. Katritzky, P. v. R. Schleyer, J. Org. Chem. 2002, 67, 1333 .

[17] J. Poater, I. García-Cruz, F. Illas, M. Solà, Phys. Chem. Chem. Phys. 2004, 6, 314.

[18] F. Feixas, E. Matito, J. Poater, M. Solà, J. Phys. Chem. A 2007, 111, 4513.

[19] F. Feixas, E. Matito, J. Poater, M. Solà, J. Comput. Chem. 2008, 29, 1543.

[20] P. J. Hay, W. R. Wadt, J. Chem. Phys. 1985, 82, 270. 
[21] J. S. Binkley, J. A. Pople, W. J. Hehre, J. Am. Chem. Soc. 1980, 102, 939.

[22] M. S. Gordon, J. S. Binkley, J. A. Pople, W. J. Pietro, W. J. Hehre, J. Am. Chem. Soc. 1982, 104, 2797.

[23] A. D. McLean, G. S. Chandler, J. Chem. Phys. 1980, 72, 5639.

[24] A. D. Becke J. Chem. Phys. 1993, 98, 5648.

[25] C. Lee, W. Yang, R. G. Parr, Phys. Rev. B 1988, 37, 785.

[26] P. J. Stephens, F. J. Devlin, C. F. Chabalowski, M. J. Frisch, J. Phys. Chem. 1994, 98, 11623.

[27] K. Woliński, J. F. Hilton, P. Pulay, J. Am. Chem. Soc. 1990, 112, 8251.

[28] Gaussian 2003: M. J. Frisch, G. W. Trucks, H. B. Schlegel, G. E. Scuseria, M. A. Robb, J. R. Cheeseman, J. A. Montgomery, Jr., T. Vreven, K. N. Kudin, J. C. Burant, J. M. M. Millam, S. S. Lyengar, J. Tomasi, V. Barone, B.Mennucci,M. Cossi, G. Scalmani, N. Rega, G. A. Petersson, H. Nakatsuji, M. Hada, M. Ehara, K. Toyota, R. Fukuda, J. Hasegawa, M. Ishida, T. Nakajima, Y. Honda, O. Kitao, H. Nakai, M. Klene, X. Li, J. E. Knox, H. P. Hratchian, J. B. Cross, C. Adamo, J. Jaramillo, R. Gomperts, R. E. Stratmann, O. Yazyev, A. J. Austin, R. Cammi, C. Pomelli, J. W. Ochterski, P. Y. Ayala, K. Morokuma, G. A. Voth, P. Salvador, J. J. Dannenberg, V. G. Zakrzewski, S. Dapprich, A. D. Daniels, M. C. Strain, O. Farkas, D. K. Malick, A. D. Rabuck, K. Raghavachari, J. B. Foresman, J. V. Ortiz, Q. Cui, A. G. Baboul, S. Clifford, J. Cioslowski, B. B. Stefanov, G. Liu, A. Liashenko, P. Piskorz, I. Komaromi, R. L. Martin, D. J. Fox, T. Keith, M. A. Al_Laham, C. Y. Peng, A. Nanayakkara, M. Challacombe, P. M. W. Gill, B. Johnson, W. Chen, M. W. Wong, C. Gonzalez, J. A. Pople, Gaussian 03, Revision B.05; Gaussian,Inc.: Pittsburgh, PA, (2003).

[29] R. F. W. Bader, Atoms in Molecules: A Quantum Theory, Oxford University Press, Oxford, U.K., 1990.

[30] F. W. Biegler-König, R. F. W. Bader, T. H. Tang, J. Comput. Chem. 1982, 3, 317. 
[31] T. M. Krygowski, J. Chem. Inf. Comput. Sci. 1993, 33, 70.

[32] P. v. R. Schleyer, C. Marker, A. Dransfeld, H. J. Jiao N. J. R. V. Hommes, J. Am. Chem. Soc., 1996, 118, 6317.

[33] (a) A. Stanger, J. Org. Chem. 2006, 71, 883, (b) J. O. C. Jiménez-Halla, E. Matito, J. Robles, M. Solà, J. Organomet. Chem., 2006, 691, 4359.

[34] M. K. Cyrański, Chem. Rev., 2005, 105, 3773.

[35] P. v. R. Schleyer, F. Puhlhofer, Org. Lett. 2002, 4, 2873.

[36] J. Poater, M. Duran. M. Solà, B. Silvi, Chem. Rev. 2005, 105, 3911.

[37] J. Poater, X. Fradera, M. Duran, M. Solà, Chem. Eur. J. 2003, 9, 400.

[38] E. Matito, M. Duran, M. Solà, J. Chem. Phys. 2005, 122, 014109.

[39] M. Gambiagi, M. Segre de Gambiagi, C. D. dos Santos Silva, A. Paiva de Figueiredo, Phys. Chem. Chem. Phys. 2000, 2, 3381.

[40] P. Bultinck, R. Ponec, S. van Damme, J. Phys. Org. Chem. 2005, 18, 706.

[41] P. Bultinck, M. Rafat, R. Ponec, B. van Gheluve, R. Carbó-Dorca, P. Popelier, J. Phys. Chem. A 2006, 110, 7642 .

[42] F. Feixas, J. O. C. Jiménez-Halla, E. Matito, J. Poater, M. Solà, J. Chem. Theory Comput., 2010, 6, 1118.

[43] K. K. Zborowski, R. Grybos, L. M. Proniewicz, J. Phys. Org. Chem. 2005, 18, 250.

[44] K. K. Zborowski, L. M. Proniewicz, J. Phys. Org. Chem. 2008, 21, 207.

[45] K. K. Zborowski, L. M. Proniewicz, Pol. J. Chem. 2004, 78, 2219.

[46] R. I. Zubatyuk, Y. M. Volovenko, O. V. Shishkin, L. Gorb, J. Leszczynski, J. Org. Chem. 2007, 72, 725.

[47] R. I. Zubatyuk, O. V. Shishkin, L. Gorb, J. Leszczynski, J. Phys. Chem. A 2009, 113, 2943.

[48] O. V. Shishkin, J. Mol. Struct. 1997, 412, 115. 
[49] O. V. Shishkin, J. Mol. Struct. 1998, 447, 222.

[50] F. Feixas, J. O. C. Jiménez-Halla, E. Matito, J. Poater, M. Solà, Polish J. Chem. 2007, 81, 797. 
Table 1. Calculated (B3LYP/6-311++G**) ASE $\mathrm{G}_{\text {iso }}$ values of the isomerization reaction from Scheme 1 for different form of the pyromeconic acid, [kJ/mol].

\begin{tabular}{lc}
\hline \multicolumn{1}{c}{ Compound } & $\mathrm{ASE}_{\text {iso }}$ \\
\hline $\mathrm{pa}^{-}$ & 77.7 \\
$\mathrm{Hpa}$ & 81.4 \\
$\mathrm{H}_{2} \mathrm{pa}$ & 118.7 \\
$\mathrm{Alpa}_{\mathrm{mer}}$ & 107.0 \\
$\mathrm{Alpa}_{\mathrm{fac}}$ & 106.1 \\
$\mathrm{Gapa}_{\text {mer }}$ & 104.5 \\
Gapa $_{\mathrm{fac}}$ & 103.9 \\
\hline
\end{tabular}




\section{Figure captions:}

Scheme 1. Reaction used for $\mathrm{ASE}_{\mathrm{iso}}$ calculations.

Scheme 2. Most important resonance structures of hydroxypyrones $\left(\mathrm{R}=\mathrm{H}, \mathrm{CH}_{3}\right.$, and $\mathrm{CH}_{2} \mathrm{CH}_{3}$ ) in neutral, anionic and cationic forms.

Figure 1. Structure of pyromeconic acid in neutral, anionic and cationic form, and the corresponding metal complexes with $\mathrm{Al}^{3+}$ (two isomers). Structures of maltol and ehylmaltol are also depicted.

Figure 2. Aromaticity data for pyromeconic acid and its metalcomplexes at the B3LYP/6$311++\mathrm{G}^{* *}$ level.

Figure 3. NICS values as a function of distance from the ring center.

Figure 4. Comparison of aromaticity data for pyromeconic acid and its metalcomplexes calculated on different basis sets. 


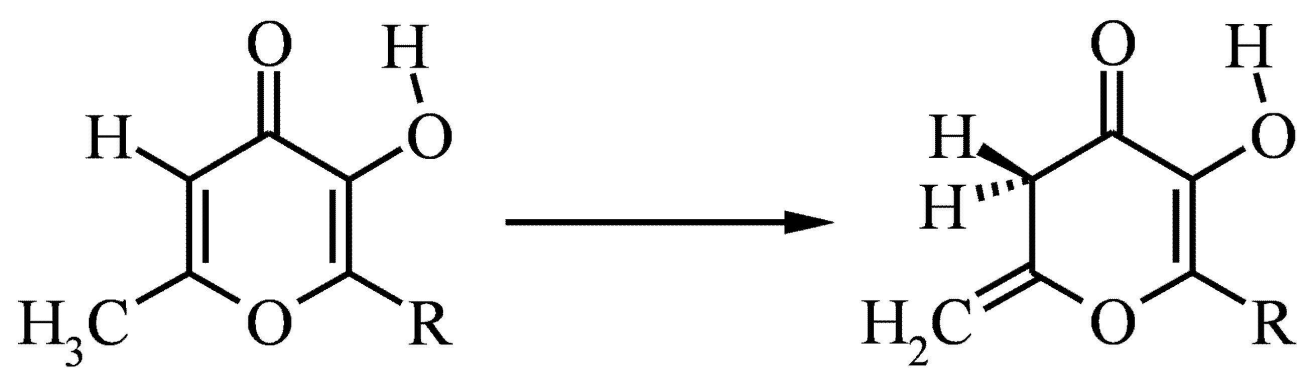




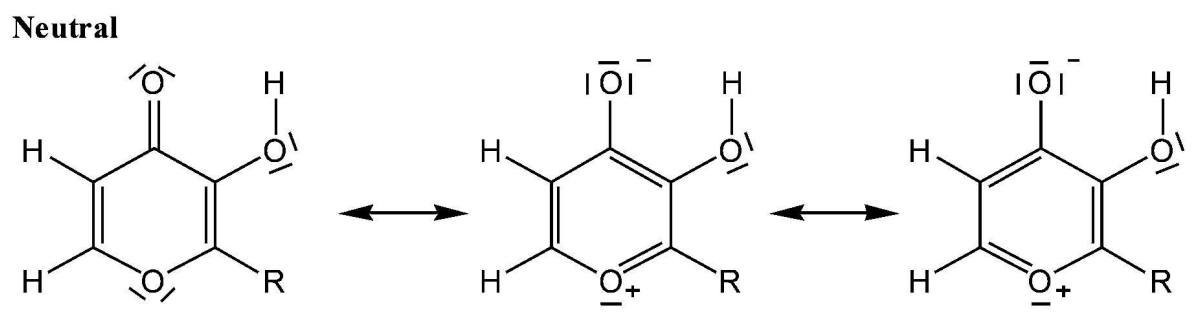

a

b

b'

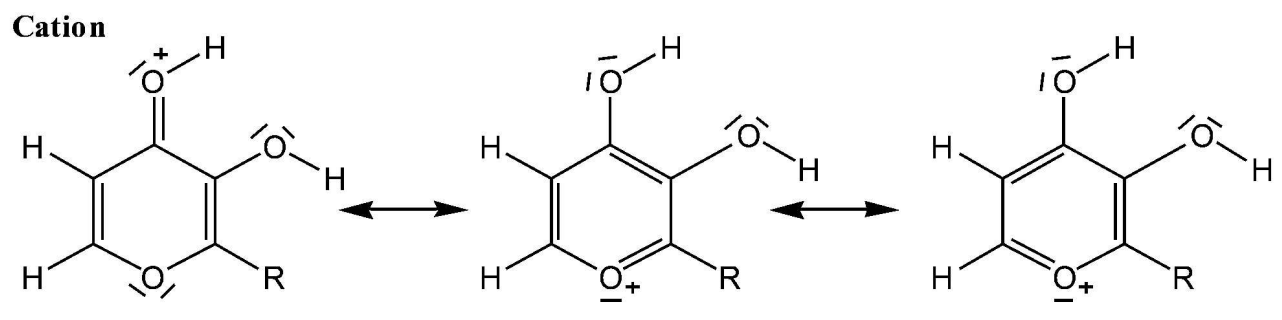

a $\quad$ b $\quad b^{\prime}$

Anion<smiles>[R]c1occ([CH])c(=O)c1[Ge]</smiles>

$\mathbf{a}$

b

$\mathbf{b}^{\prime}$ 


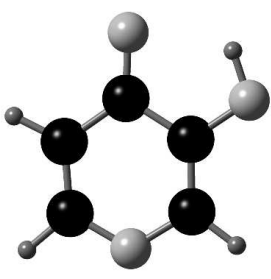

pyromeconic acid (Hpa)

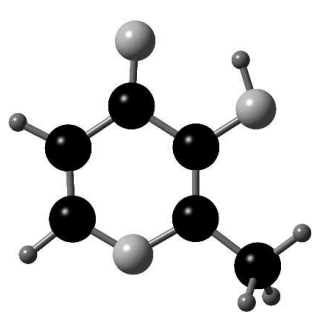

maltol

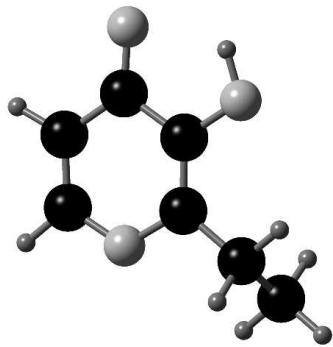

ethylmaltol

(Hema) pyromeconic acid, anion $\left(\mathrm{ma}^{-}\right)$

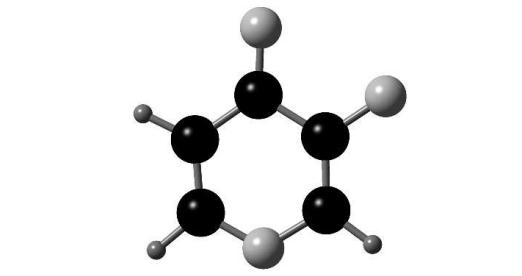

\section{2}

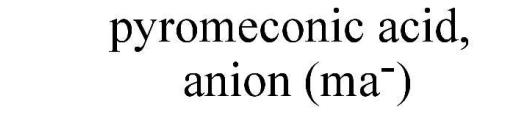
pyromeconic acid, cation $\left(\mathrm{H}_{2} \mathrm{pa}^{+}\right)$

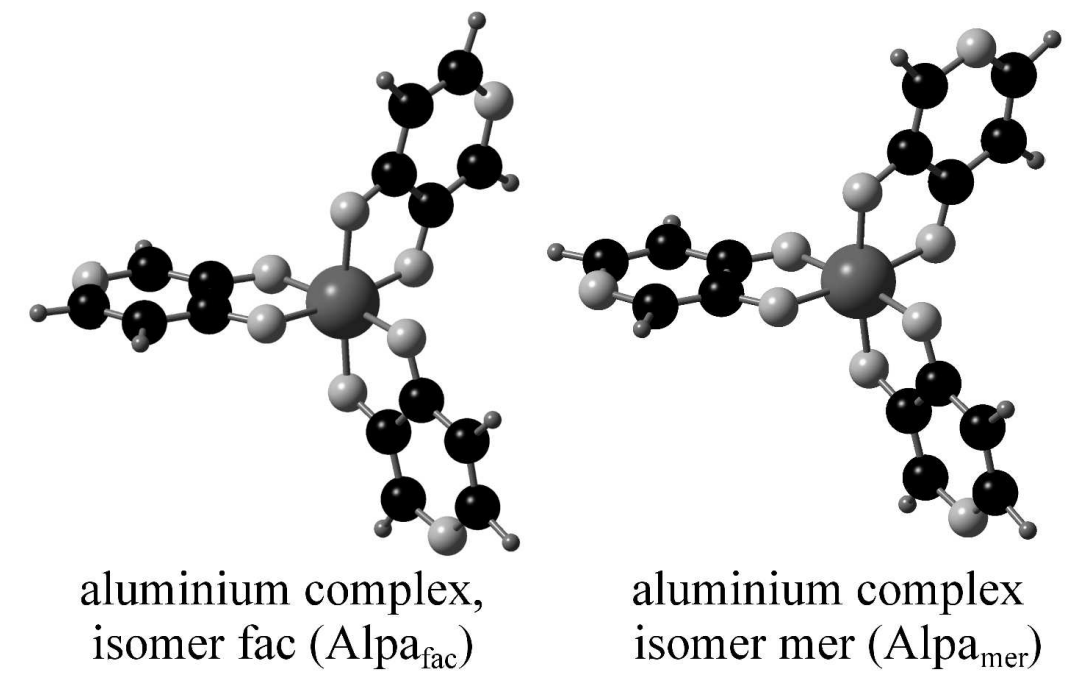

Figure 1. Structure of pyromeconic acid in neutral, anionic and cationic form, and the corresponding metal complexes with Al3+ (two isomers). Structures of maltol and ehylmaltol are also depicted. 
Page 27 of 32

Journal of Physical Organic Chemistry

1
2
3
4
5
6
7
8
9
10
11
12
13
14
15
16
17
18
19
20
21
22
23
24
25
26
27
28
29
30
31
32
33
34
35
36
37
38
39
40
41
42
43
44
45
46
47
48
49
50
51
52
53
54
55
56
57
58
59
60
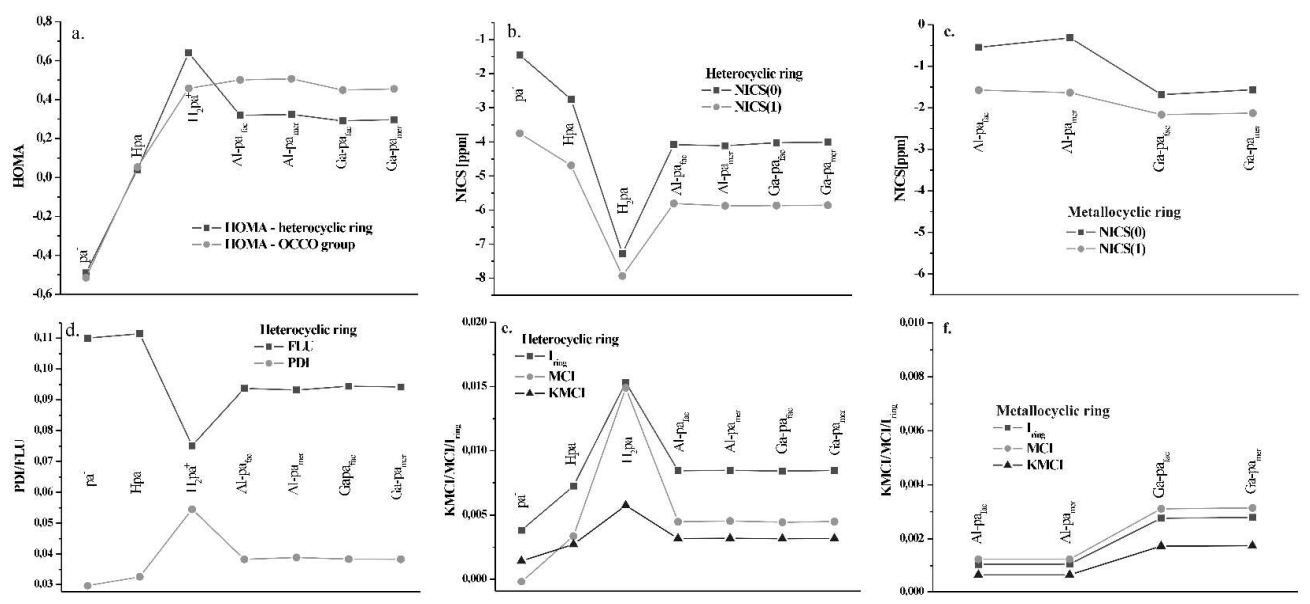

Figure 2. Aromaticity data for pyromeconic acid and its metalcomplexes at the B3LYP/6-311++G** level.

http://mc.manuscriptcentral.com/poc 

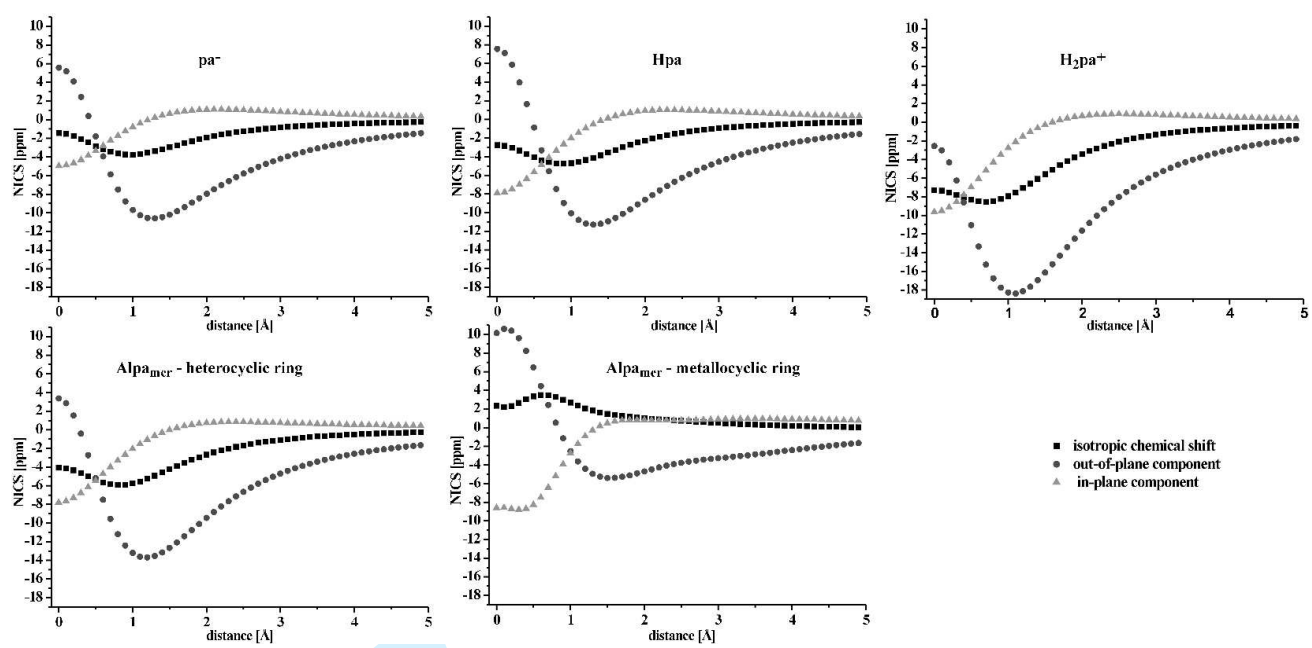

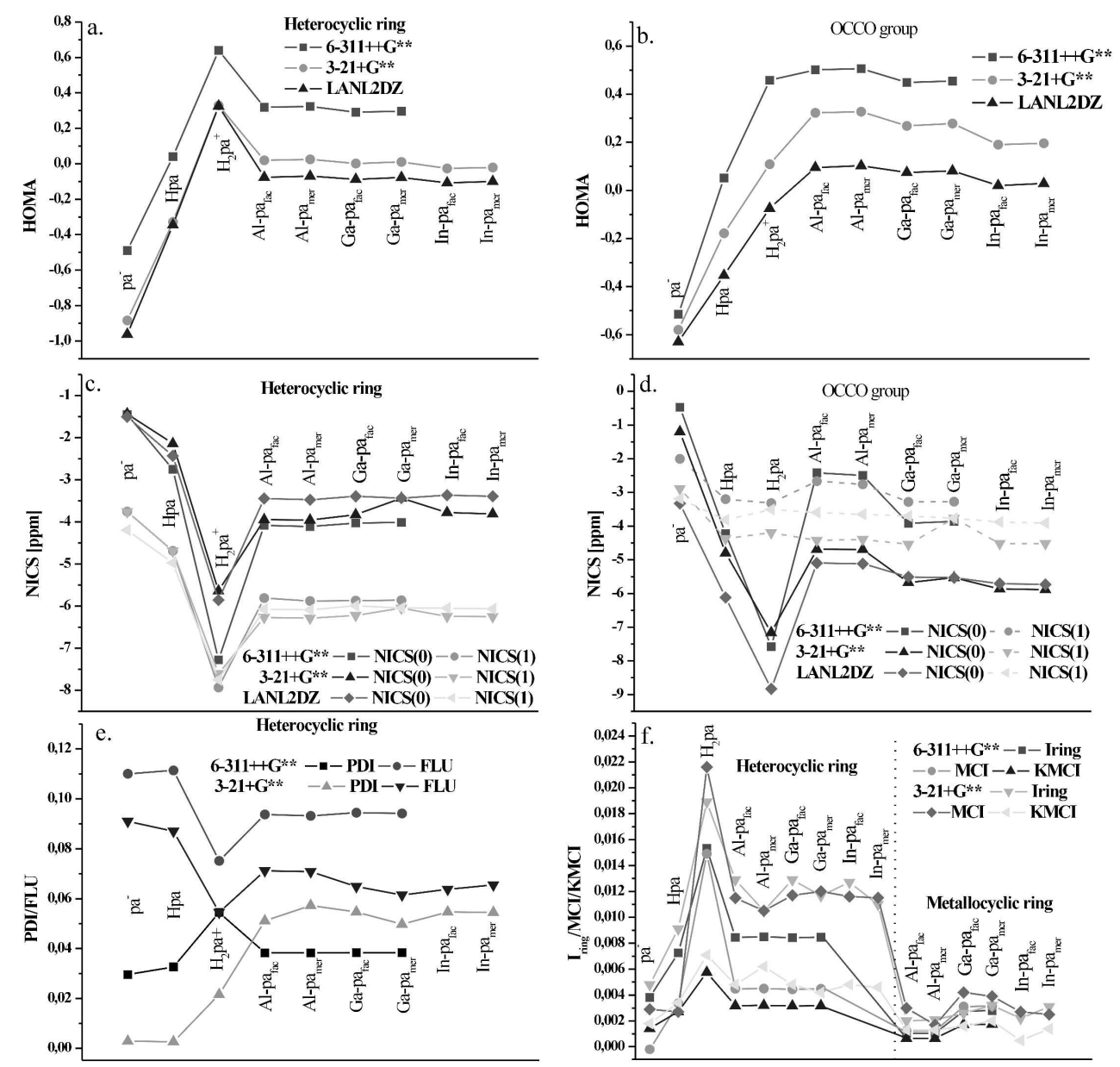
Krzysztof K. Zborowski* Miquel Solà

Jordi Poater

Leonard M. Proniewicz

Theoretical studies on aromaticity of selected hydroxypyrones. Part 3.

Chelatoaromaticity phenomenon in metalcomplexes of hydroxypyrones

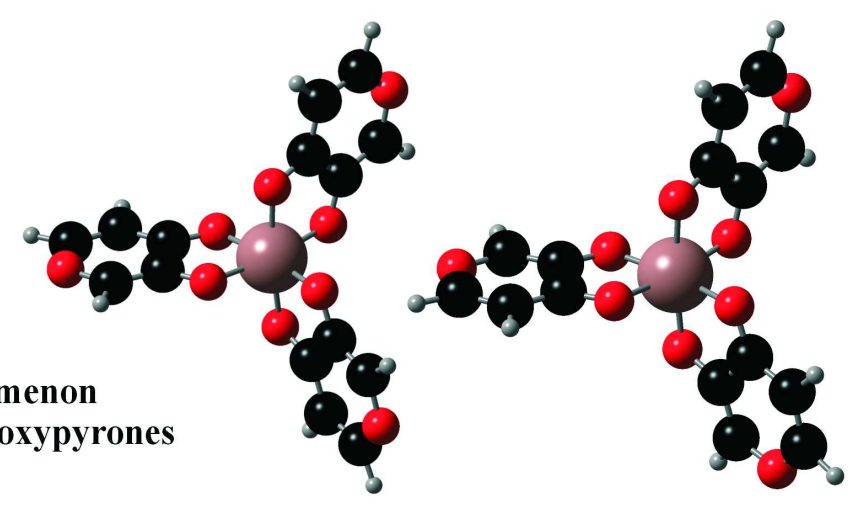

Chelatoaromaticity phenomenon is studied in complexes of pyromeconic acid, maltol and ethylmaltol with aluminium, gallium and indium cations. Calculated values of aromaticity indices show a significant increase of ligands aromaticity during complexation. This effect (effect of chelatoaromaticity) stabilizes formed chelatocomplexes. 
Table S1. B3LYP/6-311++G** aromaticity data for heterocyclic rings of studied compounds.

\begin{tabular}{|c|c|c|c|c|c|c|c|c|}
\hline & HOMA & $\operatorname{NICS}(0)$ & $\operatorname{NICS(1)}$ & PDI & FLU & $I_{\text {ring }}$ & MCI & $\overline{\text { KMC }}$ \\
\hline$\overline{\mathrm{pa}^{-}}$ & -0.49 & -1.45 & -3.75 & 0.0296 & 0.1100 & 0.0038 & 0.0002 & 0.0014 \\
\hline $\mathrm{Hpa}$ & 0.04 & -2.75 & -4.69 & 0.0326 & 0.1114 & 0.0073 & 0.0034 & 0.0027 \\
\hline $\mathrm{H}_{2} \mathrm{pa}$ & 0.64 & -7.28 & -7.93 & 0.0545 & 0.0752 & 0.0153 & 0.0149 & 0.0057 \\
\hline Alpa $_{\text {fac }}$ & 0.32 & -4.08 & -5.81 & 0.0383 & 0.0937 & 0.0084 & 0.0045 & 0.0032 \\
\hline $\mathrm{Alpa}_{\mathrm{mer}}$ & 0.32 & -4.11 & -5.88 & 0.0389 & 0.0932 & 0.0085 & 0.0045 & 0.0032 \\
\hline Gapa $_{\text {fac }}$ & 0.29 & -4.02 & -5.87 & 0.0384 & 0.0945 & 0.0084 & 0.0044 & 0.0032 \\
\hline Gapamer & 0.30 & -4.01 & -5.86 & 0.0383 & 0.0942 & 0.0085 & 0.0045 & 0.0032 \\
\hline $\mathrm{ma}^{-}$ & -0.47 & -1.27 & -3.77 & 0.0290 & 0.1186 & 0.0039 & 0.0003 & 0.0015 \\
\hline Hma & 0.08 & -2.63 & -4.58 & 0.0321 & 0.1196 & 0.0071 & 0.0037 & 0.0027 \\
\hline $\mathrm{H}_{2} \mathrm{ma}$ & 0.76 & -7.10 & -7.79 & 0.0536 & 0.0831 & 0.0146 & 0.0146 & 0.0055 \\
\hline Alma fac $_{\text {f }}$ & 0.31 & -4.03 & -5.76 & 0.0376 & 0.1030 & 0.0083 & 0.0049 & 0.0031 \\
\hline $\mathrm{Alma}_{\mathrm{mer}}$ & 0.31 & -4.02 & -5.71 & 0.0383 & 0.1022 & 0.0083 & 0.0050 & 0.0031 \\
\hline Gama $_{\mathrm{fac}}$ & 0.28 & -3.88 & -5.66 & 0.0377 & 0.1037 & 0.0083 & 0.0048 & 0.0031 \\
\hline Gama $_{\text {mer }}$ & 0.29 & -3.90 & -5.66 & 0.0382 & 0.1027 & 0.0083 & 0.0049 & 0.0031 \\
\hline ema $^{-}$ & -0.47 & -1.46 & -3.82 & 0.0289 & 0.1187 & 0.0039 & 0.0003 & 0.0014 \\
\hline Hema & 0.03 & -2.76 & -4.56 & 0.0316 & 0.1229 & 0.0069 & 0.0033 & 0.0026 \\
\hline $\mathrm{H}_{2} \mathrm{ema}$ & 0.61 & -6.99 & -7.72 & 0.0533 & 0.0839 & 0.0145 & 0.0145 & 0.0055 \\
\hline Alema $_{\mathrm{fac}}$ & 0.31 & -4.13 & -5.79 & 0.0380 & 0.1026 & 0.0083 & 0.0050 & 0.0031 \\
\hline Alema $_{\text {mer }}$ & 0.31 & -4.12 & -5.69 & 0.0384 & 0.1019 & 0.0083 & 0.0050 & 0.0031 \\
\hline Gaema $_{\text {fac }}$ & 0.28 & -4.02 & -5.70 & 0.0425 & 0.1020 & 0.0076 & 0.0046 & 0.0035 \\
\hline Gaema $_{\text {mer }}$ & 0.29 & -4.00 & -5.63 & 0.0538 & 0.1038 & 0.0079 & 0.0040 & 0.0035 \\
\hline
\end{tabular}


Table S2. B3LYP/6-311++G** aromaticity for OCCO groups/metallocyclic rings of studied compounds .

\begin{tabular}{|c|c|c|c|c|c|c|}
\hline & HOMA & $\operatorname{NICS}(0)$ & $\operatorname{NICS(1)}$ & $I_{\text {ring }}$ & MCI & KMCI \\
\hline$\overline{\mathrm{pa}^{-}}$ & -0.51 & & & & & \\
\hline $\mathrm{Hpa}$ & 0.05 & & & & & \\
\hline $\mathrm{H}_{2} \mathrm{pa}$ & 0.46 & & & & & \\
\hline $\mathrm{Alpa}_{\mathrm{fac}}$ & 0.50 & -0.55 & -1.57 & 0.0010 & 0.0012 & 0.0006 \\
\hline $\mathrm{Alpa}_{\mathrm{mer}}$ & 0.51 & -0.31 & -1.63 & 0.0011 & 0.0012 & 0.0006 \\
\hline Gapa $_{\text {fac }}$ & 0.45 & -1.68 & -2.16 & 0.0028 & 0.0031 & 0.0017 \\
\hline Gapa $_{\text {mer }}$ & 0.45 & -1.56 & -2.13 & 0.0028 & 0.0031 & 0.0017 \\
\hline $\mathrm{ma}^{-}$ & -0.40 & & & & & \\
\hline Hma & 0.06 & & & & & \\
\hline $\mathrm{H}_{2} \mathrm{ma}$ & 0.44 & & & & & \\
\hline $\mathrm{Alma}_{\mathrm{fac}}$ & 0.55 & -0.64 & -1.41 & 0.0010 & 0.0012 & 0.0006 \\
\hline $\mathrm{Alma}_{\mathrm{mer}}$ & 0.56 & -0.41 & -1.66 & 0.0010 & 0.0012 & 0.0006 \\
\hline $\mathrm{Gama}_{\mathrm{fac}}$ & 0.50 & -1.62 & -1.94 & 0.0027 & 0.0030 & 0.0017 \\
\hline $\mathrm{Gama}_{\mathrm{mer}}$ & 0.51 & -1.47 & -1.88 & 0.0027 & 0.0030 & 0.0017 \\
\hline ema $^{-}$ & -0.39 & 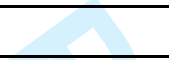 & & & & \\
\hline Hema & 0.06 & 3 & & & & \\
\hline $\mathrm{H}_{2} \mathrm{ema}$ & 0.43 & 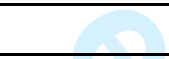 & & & & \\
\hline Alema $_{\mathrm{fac}}$ & 0.55 & -0.41 & -1.34 & 0.0010 & 0.0012 & 0.0006 \\
\hline Alema $_{\text {mer }}$ & 0.56 & -0.58 & -1.26 & 0.0010 & 0.0012 & 0.0006 \\
\hline Gaema $_{\mathrm{fac}}$ & 0.50 & -1.66 & -186 & 0.0026 & 0.0025 & 0.0020 \\
\hline Gaema $_{\text {mer }}$ & 0.51 & -1.56 & -1.83 & 0.0033 & 0.0029 & 0.0018 \\
\hline
\end{tabular}

